\title{
A PRÁTICA PEDAGÓGICA DOS PROFESSORES DE HISTÓRIA NO USO DOS LIVROS DIDÁTICOS.
}

\author{
Eliane Mimesse \\ Universidade Tuiuti do Paraná \\ emimesse@bol.com.br
}

\section{RESUMO:}

Analisam-se as práticas pedagógicas dos professores de História nas séries do ensino médio. Verificou-se como desenvolveram os conteúdos e utilizaram os livros didáticos, possibilitando classificar esses usos como do cotidiano e de pesquisa. Identificou-se como os professores apropriaram-se das sugestões contidas nos programas oficiais, a partir da análise dos conteúdos ministrados, relacionando-os aos conteúdos dos livros didáticos. Notou-se a permanência nas listagens, por longos anos, das indicações dos mesmos livros, independentemente, da redução de aulas semanais da disciplina História, fato ocorrido a partir da obrigatoriedade do ensino profissional. O período estudado trata dos anos entre 1972 e 1986, por existirem fontes disponíveis para pesquisa e contemplar a implantação e difusão da Reforma do Ensino, que entre outras alterações, incluiu novos conteúdos específicos à História. Novas sugestões de trabalho provindas dos órgãos oficiais foram publicadas, decorrendo a publicação de novos livros didáticos. As fontes usadas compõemse dos relatórios de estágios produzidos pelos alunos do curso de Licenciatura em História da Universidade de São Paulo, da legislação e dos documentos oficiais. O estudo centrouse apenas nas escolas estaduais localizadas na área metropolitana da cidade de São Paulo.

Palavras-chave: livros didáticos, história da educação, prática pedagógica.

\section{THE TEACHERS' PEDAGOGICAL PRACTICE IN THE APPLICATION OF HISTORY TEXTBOOKS.}

\begin{abstract}
:
The present study analyses the pedagogical practices of History teachers in the three last grades of basic education. The approach to subject content and the application of textbooks were examined, in which it was possible to categorize the use of textbooks as an everyday practice and source of information. The manner in which the educators made use of the suggestions of the official program is identified by the analysis of the given lessons, which were related to the content of the cited textbooks. Despite the reduction of History weekly classes, which occurred after the professional education became mandatory, the same books were still recommended on the lists. Due to the Education Reform, which included alterations in the History curriculum, and the availability of research sources, the study focuses on the years between 1972-1986. New suggestions of work were published by official organs, resulting in the publication of new textbooks. The sources of the research consist of official documents, the legislation and internship reports produced by History students from Universidade de São Paulo. The study was limited to public schools in the metropolitan area of São Paulo.
\end{abstract}

Keywords: textbooks, history of education, pedagogical practice. 


\section{Introdução}

Este estudo possibilitou verificar como os livros didáticos foram utilizados pelos professores da disciplina História nas séries do ensino de segundo grau, - como era legalmente denominado nesta época -, nas escolas públicas estaduais localizadas na área metropolitana da cidade de São Paulo. O período delimitado para essa pesquisa centrou-se entre os anos de 1972 e 1986 . O ano de 1972 justifica-se por contemplar a implantação da Reforma do Ensino, e o ano de 1986 por trazer os últimos indícios do uso cotidiano de livros didáticos. As fontes foram os relatórios de estágios ${ }^{1}$, produzidos pelos alunos para a disciplina de Prática de Ensino no curso de Licenciatura em História da Universidade de São Paulo.

A utilização dos relatórios de estágios como fontes primárias propiciaram as mais diversas análises sobre os livros didáticos. Fez-se uso, para compor o panorama do período, de documentos produzidos pelos órgãos do governo, federal e estadual, referentes a metodologia de ensino, como também dos livros didáticos citados pelos professores.

Todos os relatórios referentes a Disciplina de Prática de Ensino de História produzidos nas décadas de setenta e oitenta foram lidos e analisados. Efetuada a análise pôde-se mapear quais eram os livros didáticos utilizados pelos professores das séries do segundo grau. Os comentários existentes nos relatórios, elaborados pelos alunosestagiários, sobre os livros didáticos e a metodologia de ensino dos professores foram utilizados neste texto no sentido de apresentar ao leitor como as aulas eram desenvolvidas na prática. Todos os livros didáticos citados pelos professores como de uso corrente foram analisados.

O texto será desenvolvido em itens que abordam o currículo oficial e a metodologia de ensino do professor, o guia metodológico do governo federal da década de setenta, os usos dos livros didáticos pelos professores, e a proposta curricular estadual do governo paulista datada de 1980 .

\section{O currículo e a metodologia de ensino do professor.}

Pôde-se verificar, segundo a análise das fontes, que os professores transitaram entre obras mais antigas reconhecidas na área e livros didáticos produzidos, muitas vezes, em decorrência da publicação de sugestões curriculares oficiais. Os conteúdos desenvolvidos nas aulas dependiam das práticas pedagógicas adotadas pelos professores e das relações estabelecidas com os alunos, com os materiais didáticos e com os programas oficiais. $\mathrm{O}$ currículo oficial estabelecia conteúdos mínimos e, era elaborado por pesquisadores e docentes que nem sempre conheciam as diversidades e as especificidades das salas de aulas. Esse currículo trazia sugestões de atividades adequadas a cada conteúdo proposto. $\mathrm{Na}$ maioria das vezes, ele era apresentado aos professores pelos livros didáticos que os adaptavam, sem expressarem de modo aprofundado os conteúdos sugeridos pelo currículo oficial. Batista (2002) reforçou essa idéia quando comentou que os livros didáticos acabavam assumindo as funções expressas pelo currículo.

Quando os professores interpretavam esse material, utilizavam suas experiências, analisavam o contexto para o desenvolvimento das aulas e as possibilidades de assimilação dos conhecimentos pelos alunos. Esta análise deveria colocar as prescrições do currículo oficial em ação que, na prática, segundo Sacristán (2000, p. 105) o currículo "é guiado pelos esquemas teóricos e práticos do professor e se concretiza nas tarefas acadêmicas, [...] sustenta o que é a ação pedagógica, assim podemos notar [...] o que são as propostas curriculares." 
No mesmo sentido desta interpretação, tem-se a explicação do estagiário em seu relatório de observação. O aluno-estagiário no ano de 1985 descreveu como identificou o currículo e suas influências na prática do professor:

O currículo é um dos instrumentos que procura sobredeterminar o conteúdo da matéria a ser ensinada, como proposta de curso a ser adotada, ou que até efetivamente sobredetermina esse conteúdo, na medida em que é adotado cumprido a-criticamente por grande parte os professores, é o currículo oficial. Geralmente, quando não se segue o currículo oficial, seguem-se os livros didáticos, outra autoridade. O currículo oficial traduz o papel que o Estado atribui à História, através dos conteúdos e atividades sugeridas. (RELATÓRIO 10, 1985)

Portanto, será a prática pedagógica de cada professor que vai colocar em ação, segundo as suas interpretações, o currículo, com suas sugestões de conteúdos mínimos, exercícios e métodos de ensino. Mas os livros didáticos tornaram-se a fonte das informações contidas no currículo prescrito, submetendo os docentes a seus desígnios. Os materiais didáticos são importantes para a aplicação do currículo porque, segundo Sacristán (2000, p. 157), "são os tradutores das prescrições curriculares gerais, são os divulgadores de códigos pedagógicos, e são recursos muito seguros." É possível concordar plenamente com as palavras do autor, quando nos relatos dos professores verificou-se o uso de livros didáticos de outras séries de ensino, adotados por eles como base para suas pesquisas.

A prática dos professores é, ainda para o mesmo autor, uma "prática institucionalizada", decorrente das influências externas e das relações ensino-aprendizagem e professor-aluno. $\mathrm{O}$ autor observou que os pais e os professores identificavam certos conhecimentos como mais valiosos e induziam os alunos à aceitação desses. O conflito sobre quais conteúdos abordar surgiu quando se pretendeu mudar os que eram considerados adequados pela comunidade. Tratando-se do ensino de História as especificidades eram mais amplas, os conteúdos da disciplina eram entendidos pelos pais como de domínio comum, e esses pais consideravam a possibilidade de intervir e opinar sobre o quê e como o professor deveria ensinar determinados conteúdos.

\section{O Guia Metodológico do governo federal.}

Na década de 1970, o ensino de História no segundo grau (atualmente denominado de ensino médio) tinha suas diretrizes estabelecidas pelos Guias Metodológicos divulgados pelo Ministério da Educação e Cultura, que orientavam os professores sobre os conteúdos mínimos a serem ministrados e os métodos mais adequados a estas séries. O Guia Metodológico para cadernos MEC- História, lançado em 1971, pretendia colaborar com a aplicação dos conteúdos dos Cadernos MEC: História Geral 1- Antiga e Medieval e Cadernos MEC: História Geral 2 - Moderna e Contemporânea, publicados na década anterior. Os professores que elaboraram este e outros volumes assinalavam a necessidade de uma formação cultural ampla do professor de segundo grau, além de adequada preparação pedagógica. Essa publicação, segundo seus autores, não pretendia guiar os professores nos seus atos, apenas apresentar-lhes um roteiro com orientações. Visava também, à articulação das informações entre os professores das oito primeiras séries e os das três ou quatro séries seguintes.

Esse Guia trazia considerações sobre a profissionalização nas últimas séries do segundo grau. Continha informações sobre a redação e organização dos objetivos do planejamento escolar, a importância do estudo da História, formas adequadas de se abordar 
um fato histórico, como escolher o melhor e mais interessante livro didático, quando fazer uso de mapas, Atlas e recursos audiovisuais, como coordenar uma discussão temática em sala, a importância das atividades extraclasses e modelos de avaliações.

Segundo as recomendações do Conselho Federal de Educação, as aulas de História deveriam ser desenvolvidas, visando à unificação da História universal com a do Brasil. Devendo-se destacar a História das civilizações do continente americano e a História contemporânea e, complementando este conteúdo com a História dos outros continentes, especialmente a Ásia e a África. O mesmo Conselho Federal recomendava a existência da disciplina, com os conteúdos sugeridos, em "todas as séries da escola de nível médio, sem incluir a terceira, que teria seu currículo construído de acordo com as solicitações do vestibular", caso houvesse a manutenção de cursos regulares.

A existência deste Guia concorreu para a inexistência de um guia paulista específico para o ensino de História nas séries do segundo grau. Nos relatórios de estágios do período de 1972 a 1976, os conteúdos abordados eram de História geral e História do Brasil, e tratavam apenas da $1^{\mathrm{a}}$ e da $2^{\mathrm{a}}$ séries. Os conteúdos sugeridos pelo Conselho Federal de Educação sobre a inserção de História dos povos do continente americano e de outros continentes não foi contemplada nas aulas observadas. Pôde-se inferir, neste sentido, que os conteúdos mínimos propostos pelo citado Guia não foram contemplados, perpetuando a manutenção dos conteúdos e consequentemente da prática pedagógica préexistente. Os estágios na $3^{a}$ série foram citados apenas no ano de 1977 . De acordo com Mimesse (2007), a falta de dados nos relatórios de estágios sobre a efetivação de observações ou regências nas $3^{\text {a }}$ séries do ensino de segundo grau talvez, decorra do fato de que os estágios realizavam-se nas escolas com cursos profissionalizantes, por conseguinte, continham as disciplinas básicas concentradas principalmente nas duas primeiras séries.

Faz-se necessário, neste momento, esclarecer brevemente sobre os estágios nos cursos profissionalizantes obrigatórios no ensino de segundo grau. Legalmente, todos os estabelecimentos deste nível de ensino, deveriam implantar o ensino profissional após a promulgação de sua obrigatoriedade pela Reforma de Ensino de 1971. Mas, segundo Mimesse (2007) as várias dificuldades de implantação desta modalidade de ensino contribuíram para a criação de outras possibilidades de formação. No ano de 1972 apenas os estabelecimentos de ensino privados e públicos municipais apresentaram ao órgão competente um plano de trabalho para a organização didática e administrativa a ser implantada nas séries do ensino de $2^{\circ}$ grau. Nas escolas da rede pública estadual o ensino profissional de $2^{\circ}$ grau passou a funcionar regularmente a partir de 1977 , este foi o momento em que ocorreu a criação de uma nova habilitação no Estado de São Paulo, denominada Formação Profissional Básica. Essa modalidade adaptou as disciplinas existentes à nova situação escolar.

Essa referida adaptação das disciplinas suprimiu as aulas de História nas últimas séries do ensino de segundo grau, já que as disciplinas do chamado núcleo comum compunham a grade curricular das duas primeiras séries deste nível de ensino. Quando os estagiários referiam-se ao estágio em turmas de $3^{\text {a }}$ série no ano de 1977 , considerou-se que seria porque neste momento as escolas estaduais haviam colocado em prática as instruções da nova modalidade de habilitação. E, desta forma, consequentemente, existiria o curso no setor terciário com aulas da disciplina História nas três séries.

\section{Os livros didáticos e seus usos.}

Os livros didáticos foram referenciados e indicados nos relatórios de estágios, como de uso efetivo pelos professores nas séries do segundo grau, eram utilizados de duas 
formas: como manuais e como livros de pesquisas. Quando usados como manuais, tinham a função de complementar a aula expositiva, com a apresentação de textos, exercícios e resumos sobre os conteúdos; como livro de consulta ou de pesquisas, apenas parte de seus textos eram aproveitados. Alguns livros didáticos assumiram o papel de livros de pesquisa, talvez porque o professor considerasse que nenhum dos livros disponíveis no mercado abrangesse todos os conteúdos necessários, ou mesmo, em decorrência da falta de condições financeiras da maioria dos alunos para a sua aquisição. Carbone (2003) indicou em seu texto que era uma prática o uso de livros que não eram designados originalmente como manuais, eles apenas tinham a função de complementar os conteúdos. Em relatório de 1977, o estagiário explicou a atitude do professor, que encontrou uma solução para a aquisição do livro:

Atualmente, o professor deixou em aberto o uso do livro didático. Cada qual utiliza aquele que tiver a mão. Porque, segundo o professor contatado, ano após ano vem tentando modificar seu modo de dar aula. Já procurou, por exemplo, pedir aos alunos que apenas acompanhem as explicações, fazendo uma ou outra anotação, mas os resultados não foram satisfatórios. Em outra oportunidade, optou pela adoção de livro didático, mas, pessoalmente, sentiu-se muito preso a ele e obcecado por vencer o conteúdo. (RELATÓRIO 3, 1977)

Outro estagiário, no mesmo ano, citou o que ocorria quando os alunos de uma sala tinham o livro didático. De acordo com o parecer da professora, essa situação era um avanço, porque criava a possibilidade de usar outra metodologia de ensino, diferente da adotada nas séries do primeiro grau. Mas, para os alunos, a forma como o livro era utilizado tornava as aulas monótonas e cansativas:

A professora havia me dito que para o colegial era possível dar aulas expositivas, e que os alunos, além de outras atividades do curso, tinham que ler os capítulos do livro didático e elaborar um fichamento que lhe era entregue como parte dos requisitos de avaliação. No entanto em entrevista que mantive com os alunos, eles me disseram que o livro didático era lido em classe, e que isto tornava as aulas monótonas, porque os capítulos são muitos extensos e a forma como eram dadas estas aulas tornava-as cansativas. (RELATÓRIO 7, 1977)

O Guia Metodológico para cadernos MEC - História sugeria maneiras para o professor explorar o livro didático com os alunos, a partir de trabalhos individuais ou em grupos. Indicava estudos do vocabulário acompanhados de pesquisas em dicionários, elaboração de resumos e de esquemas, comparação entre textos - quando os alunos utilizavam livros diferentes, e análise das ilustrações.

Foram poucos os livros utilizados pelos professores do ensino de segundo grau nas décadas estudadas. Segundo os dados colhidos nos relatórios de estágios verificou-se que os livros de História eram indicados para compra, mas nem sempre adquiridos pelos alunos. A soma total de obras indicadas e adotadas chegou a 13. Essa quantidade reduzida pode ser explicada porque os alunos não consideravam a História uma disciplina de primeira linha e nem todos os professores usavam manuais, argumentando que eles próprios dominavam os conteúdos e que os manuais nem sempre eram completos. Um estagiário no Relatório 4 (1977), por sua vez, comentou o "problema do status" da disciplina História, que para os alunos era vista "como matéria de segundo plano, decorativa, que não tinha necessidade de aprenderem". 
O Guia Metodológico enfatizava a necessidade do uso do livro didático nas séries do segundo grau como auxiliar básico do professor, desde que bem trabalhado. E ainda indicava que o bom professor deveria analisar os livros didáticos escolhidos pelos alunos, quando esses traziam para as aulas manuais diferentes.

As aquisições dos manuais dependiam das condições financeiras das famílias e do acervo da biblioteca escolar. A prática dos alunos de usar o livro didático que tivessem acesso interferiu no uso cotidiano dos manuais, porque nem todos traziam as mesmas informações, o que desfavorecia seu uso continuado. O professor citado, no relatório de 1977, permitiu que os alunos utilizassem o livro que "tivessem à mão". Essa atitude do professor pode ser entendida, como a apresentada por Batista (2002) e por Carbone (2003), que por sua vez, indicou em sua pesquisa a dependência do professor com relação aos livros didáticos, porque estes poderiam ser entendidos como "ajudas sempre à mão".

$\mathrm{Na}$ década de 1970, foram três os livros didáticos verificados nas fontes como de uso cotidiano pelos professores nas séries do segundo grau. No ano de 1972 foram citados os de Souto Maior, História geral para o ensino de $2^{\circ}$ grau e vestibulares e o de Esaú e Gonzaga, História do Brasil: estudo dirigido; nos anos de 1974 e 1975 o livro de Esaú e Gonzaga foi novamente referido e o de José Jobson de Andrade Arruda, História moderna e contemporânea.

Os conteúdos destes livros didáticos poderiam ser relacionados às sugestões contidas no documento do Conselho Federal de Educação. Os autores vinculavam conteúdos de História do Brasil com a História geral. Nos dois livros de História geral existiam capítulos sobre o imperialismo europeu e a descolonização nos continentes africano e asiático e sobre a América do Norte e Latina. O livro de Esaú e Gonzaga de História do Brasil continha mapas e gravuras e, no fim de cada subitem, uma série de exercícios, de modo que metade das páginas de cada capítulo era composta por atividades. Um relatório de estágio de 1975 apresentou parte dos programas da $1^{\text {a }}$ e da $2^{\text {a }}$ séries, copiados da lousa pelo estagiário, que os identificou aos conteúdos listados no sumário "do manual adotado na sala, de José Jobson, História Moderna e Contemporânea, Ática, 1974".

Durante toda a década de 1970, poucos foram os livros indicados como de pesquisa. Identificou-se o uso de apenas três livros citados pelos professores com a função de livros de pesquisa. Mas pôde-se notar que, algumas vezes, esses mesmos livros foram indicados como livros didáticos. Eram eles: História da civilização ocidental (vol. 1 e 2) de Edward MacNall Burns; História da riqueza do homem de Leo Huberman e História econômica do Brasil de Caio Prado Júnior.

O livro de Burns foi utilizado por um professor para "dar aos alunos não só informação, mas principalmente uma formação", segundo sua própria citação em relatório de 1972. Notou-se, também, que as obras de Huberman e Prado Júnior adotavam uma perspectiva marxista e criticavam a ascensão de uma elite e do capital, em detrimento da classe trabalhadora, produtora das riquezas humanas. O uso do livro de Huberman como didático também ocorreu nas séries do segundo grau e foi complementado pelo manual de Arruda. Neste caso, o professor pretendia atingir "seu objetivo maior: a formação de hábitos e a reflexão", como expresso em relatório de 1974. É interessante notar que essas obras, usadas como livros de pesquisa e em dois casos como didáticos, foram publicadas pela primeira vez havia já pelo menos três décadas, o que faz sugerir a hipótese de que haviam sido utilizadas pelos professores quando estes cursaram a graduação.

O ímpeto que levou alguns dos professores das escolas estaduais a usar livros para as pesquisas dos alunos também os levou a adotar livros didáticos. A opção, por alguns destes livros para pesquisa e ensino nas séries do segundo grau, talvez tenha ocorrido em 
função da amplitude dos conteúdos de História geral ou pela escassez de dados na maioria dos livros didáticos de História sobre a economia brasileira, ou ainda por não apresentarem de modo detalhado o processo de implantação e sedimentação do sistema capitalista.

\section{A Proposta Curricular e os usos dos livros didáticos.}

Em 1980, foi publicada a Proposta Curricular de História e Geografia para o $2^{o}$ grau cuja novidade era introduzir conteúdos de História da América. Essa Proposta trazia, para cada série, os objetivos, a sugestão programática e de conteúdo, e uma extensa bibliografia. No fim do volume, encontravam-se sugestões de atividades para o professor utilizar com os alunos, fazendo uso de livros, explicitando modos de desenvolver a leitura e formas de comparar textos, de usar enciclopédias, quais temas poderiam estudar, como elaborar um levantamento bibliográfico, redigir trabalhos, produzir e utilizar mapas e gráficos, desenvolver dissertações, relatórios, debates e apresentações de pesquisas.

Os conteúdos foram separados de acordo com os temas: História e Geografia da América para a $1^{\mathrm{a}}$ série, História e Geografia do Brasil para a $2^{\mathrm{a}}$ série. Nos conteúdos da $2^{\mathrm{a}}$ série, deveriam ser inseridos aspectos de História geral e de Geografia geral moderna e contemporânea para, necessariamente, complementar as explicações sobre a História do Brasil. Quando os alunos freqüentavam o curso de segundo grau com habilitação na modalidade Formação Profissional Básica do setor terciário, teriam três horas aulas semanais de História administrativa do Brasil e, assim, os conteúdos seriam aprofundados nas $2^{\mathrm{a}}$ e nas $3^{\mathrm{a}}$ séries.

Essa modalidade denominada Formação Profissional Básica, foi criada no início de 1977 e conseguiu sanar as dificuldades de implantação do ensino profissional na maioria das escolas estaduais de segundo grau. De acordo com Mimesse (2007), era indicada a todos os estabelecimentos de ensino de segundo grau estaduais que não possuíssem condições de oferecer habilitações profissionais, nas escolas em que os estudantes demonstrassem interesse em cursá-la e nas que mantivessem apenas a Habilitação Específica de $2^{\circ}$ grau para Magistério - era a nova denominação para o antigo Curso Normal. Com a implantação dessa modalidade as aulas de História concentravam-se nas duas primeiras séries, dos cursos voltados para o setor primário e secundário, somente no curso do setor terciário as aulas de História estendiam-se até a terceira série, como já foi explicado anteriormente.

Nos conteúdos sugeridos para as três séries nas aulas de História, verificou-se que, na $1^{a}$ série, concentravam-se na História da América do Norte e da América Latina vinculados à História do Brasil; na $2^{\mathrm{a}}$ série, na História do Brasil imperial e republicano; nas $2^{\mathrm{a}}$ e na $3^{\mathrm{a}}$ série do setor terciário, os conteúdos focalizam a História política e administrativa do Brasil a partir da influência dos colonizadores, dos ideais de liberdade de outros povos, das ascensões e crises econômicas européias.

$\mathrm{Na}$ análise dos conteúdos, a partir dos relatórios de estágios percebeu-se que alguns anos não são indicados por não existirem relatórios, ou por não ter ocorrido estágio nas séries do segundo grau. Alguns dos conteúdos citados eram similares: era o caso do Renascimento, da História geral e da Europa Moderna. Uma hipótese explicativa para tal acontecimento, segundo um dos relatórios de estágios do ano de 1978, é o caso de um professor que abordava o mesmo assunto em todas as séries em que lecionava, para sanar as lacunas da aprendizagem dos alunos e perder pouco tempo na preparação das aulas.

Após o ano de 1978, foi possível notar a influência da Proposta Curricular de História e Geografia nos conteúdos das séries. Identificaram-se assuntos diretamente vinculados aos sugeridos pelo programa oficial. Apesar dos argumentos, existentes nas 
publicações, incentivando mudanças metodológicas em sala de aula, uma professora relatou que se utilizava das sugestões da Proposta de História e Geografia, mas ainda demonstrava, de acordo com o estagiário no ano de 1985:

[...] uma grande preocupação com fatos específicos (nomes e datas). $\mathrm{O}$ encadeamento destes fatos é determinado por relações simplistas de causa e efeito. O que se veicula é uma visão da História fragmentária e factual, em detrimento da reflexão e compreensão dos processos históricos. (RELATÓRIO 8, 1985)

Com a análise desta citação acima, pôde-se identificar como a assimilação metodológica, a partir da implantação de uma nova modalidade de habilitação era diametralmente oposta - quando se referia à reorganização dos conteúdos específicos de uma disciplina. Independentemente das sugestões contidas nos documentos oficiais, a prática pedagógica individual persistia dentro de cada sala de aula. A manutenção da prática no ensino de determinados conteúdos permaneceu de modo tácito arraigada ao cotidiano da escola.

Mas, mesmo com estas demonstrações das posturas dos professores alguns livros didáticos foram adotados entre os anos de 1977 e 1985. Existiu o predomínio dos livros de História geral, seguidos pelos de História do Brasil e da América. Eram eles respectivamente: os de Esaú e Gonzaga, História do Brasil: estudo dirigido e História geral da civilização; o de José Jobson, História moderna e contemporânea; o de Souto Maior, História geral para o ensino de $2^{\circ}$ grau e vestibulares; o de Antonio Pedro e Florival Cáceres, História geral; o de Heródoto Barbeiro, História geral; o de Elza Nadai e Joana Neves, História da América; o de Koshiba e Pereira, História do Brasil; o de Piletti, História do Brasil; e o de Antonio Pedro, História moderna e contemporânea.

Esses livros de História geral assemelhavam-se, na apresentação dos conteúdos, aos já citados livros usados para os trabalhos de pesquisa. Traziam como diferenciais algumas gravuras, fotografias, mapas e quadros cronológicos, além de resumos no fim dos capítulos. Isto ocorreu com os livros de Souto Maior, Arruda, Pedro e Cáceres, Pedro e de Barbeiro. Outro ponto a destacar era a existência de questionários ou de orientações para a leitura auxiliar, em forma de questões, que apareceram nos livros de Pedro e Cáceres e de Barbeiro. A cronologia, o vocabulário e os trechos de documentos surgiam apenas nos livros de Arruda, de Barbeiro e de Pedro. Pode-se afirmar, pelos dados colhidos nos relatórios de estágios, que os professores faziam uso destes manuais como livros de leitura. Eram utilizadas as ilustrações e mapas para breves comentários e dificilmente os exercícios foram resolvidos em sua totalidade.

Os livros de Esaú e Gonzaga eram apresentados de modo diferente dos outros, com muitas ilustrações coloridas; os mapas incluíam figuras humanas, e em todas as páginas desenhos acompanhavam o texto - em algumas, o conteúdo era apresentado na forma de história em quadrinhos. Existiam, no decorrer do texto, lembretes e definições de conceitos. A obra não contava com nenhum tipo de exercício em todo o volume, talvez por ter um caderno de exercícios que o acompanhasse. Um grupo de estagiários ${ }^{2}$, em 1978, comentou os livros desses autores:

Quanto ao livro adotado, soubemos que o professor adotou um no princípio do ano, o qual serve como guia aos alunos e embora nos pareça falho em muitos aspectos, aos olhos dos estudantes é bastante claro, objetivo e fácil de ser decorado, características estas que agradam muito a todos os alunos. (RELATÓRIO 6, 1978) 
Dos livros utilizados pelos professores no segundo grau, apenas os de Barbeiro e de Arruda, autores de obras de História geral, demonstravam a preocupação de vincular os conteúdos da História geral com os da História do Brasil. O volume de Arruda apresentava um diferencial na maneira de abordagem dos conteúdos, que era o de utilizar-se de uma perspectiva marxista, os conteúdos eram expostos segundo as esferas do econômico e do social, aos quais eram acoplados, no desenrolar do texto, os aspectos políticos e culturais. Acrescentou-se, também, a preferência pelo estudo de temáticas, consideradas pelo autor como fundamentais e capazes de orientar sobre os acontecimentos mais recentes. Esta maneira de apresentar os conteúdos não era oferecida por nenhum outro livro didático na década de 1970. O livro de Arruda foi citado em vários dos relatórios, duas professoras, em 1977, fizeram considerações sobre este livro.

A professora demonstra seu descontentamento com o livro didático adotado pela escola (Jobson Arruda). Considera-o fraco, incompleto nos dados, nas datas, etc... Justifica-se dizendo utilizá-lo por não ter como se impor num terreno mal conhecido e demonstra clara preferência por outro livro didático. (RELATÓRIO 3, 1977)

E a segunda

O livro que considera ideal para o estudo de História nesta série é a obra do professor Jobson de Arruda, editado em dois volumes: História Antiga e Medieval e História Moderna e Contemporânea porque segue a linha da História sócio-econômica, que é o enfoque que a professora considera mais importante. Mas não adota o livro, porque o preço não é acessível aos seus alunos, além do que seria necessário adotar uma outra obra para o estudo de História do Brasil, o que encareceria ainda mais. (RELATÓRIO 5, 1977)

Os relatos acima demonstraram quais eram as impressões causadas pelo livro em questão. Era considerado indevido para uns e, ao mesmo tempo, indicado por outros. Essa controvérsia sobre este volume ainda permaneceu na década de 1980.

Os livros de História do Brasil citados foram utilizados em épocas diferentes. O de Esaú e Gonzaga, em 1978, no mesmo ano da Proposta Curricular de História e Geografia; os de Koshiba e Pereira e de Piletti, em 1985, quando as sugestões da Proposta já estavam mais sedimentadas. Apenas as obras de Piletti e, Koshiba e Pereira apresentavam a História do Brasil até a década de 1980, o que demonstrava preocupação com a atualização das informações que seriam adquiridas pelos alunos. Continha questões para os alunos responderem no encerramento de cada capítulo, além de trechos de documentos acompanhados de perguntas. O livro de Piletti indicava ainda uma pequena bibliografia, no fim de cada capítulo, para aprofundamento dos assuntos.

Os comentários sobre os conteúdos existentes no fim dos capítulos eram, até certo ponto, propositais. Nos depoimentos analisados nos relatórios de estágios identificou-se, claramente, que dificilmente os professores conseguiam alcançar os conteúdos mais atuais constantes no final do volume usado. Supõe-se a existência de um acordo tácito sobre os conteúdos da disciplina História, por serem esses considerados muito extensos e com muitos detalhes para serem aprofundados; justificando assim, o término das explanações dos professores - no mínimo - cinco décadas antes do período por eles vivido.

O livro de Nadai e Neves, de acordo com a introdução das próprias autoras, tinha como objetivo "assegurar um conhecimento preciso e global sobre a realidade americana e, 
ao mesmo tempo, o domínio da técnica de estudo que dará independência e iniciativa para melhor organizar os estudos posteriores". Os conteúdos foram divididos em América précolombiana e da colonização européia; Estados Unidos; e América Latina. Essa era a mesma divisão dada aos conteúdos pela Coletânea de documentos de História da América para o $2^{o}$ grau - $1^{a}$ série, que seria publicada dois anos depois deste livro, pela Coordenadoria de Estudos e Normas Pedagógicas da Secretaria de Estado da Educação de São Paulo. No livro existiam mapas e ilustrações, no fim de cada capítulo, existiam textos denominados como de "Leitura complementar", eram acompanhados de pequenos trechos de documentos que os reforçam, além de questões para serem respondidas no próprio livro.

Esta referida obra foi pioneira na apresentação de conteúdos sistematizados de História da América, pois as autoras participaram de algumas das equipes que formularam propostas de ensino e, Nadai fez parte da equipe que elaborou a Proposta Curricular de História e Geografia. Desta forma, a publicação deste volume contribuiu para a difusão dos documentos oficiais a partir de um livro didático, facilitando o acesso dos professores aos conteúdos específicos por esta via. Batista (2002) comentou em seu texto sobre a produção didática afirmando que essa era "quase sempre um campo em que o Estado atua diretamente", neste caso estudado houve a atuação do Estado, mas de modo indireto.

Em 1981, foi publicada a Coletânea de documentos de História da América para o $2^{o}$ grau - $1^{a}$ série, com a pretensão de ampliar as opções de material didático usado pelos professores da disciplina, contribuir com a implantação da Proposta Curricular de História e Geografia e dar continuidade ao trabalho desenvolvido na Coletânea de documentos para o $1^{o}$ grau. Nesta Coletânea de História da América, a equipe responsável procurou enfocar o homem como agente do processo histórico, optando pelo estudo temático dos países latinoamericanos. Ao apresentar ao leitor os documentos - alterados sem mudar o sentido original, visando à melhor compreensão dos alunos-, explicaram-se suas origens e os prováveis motivos de sua redação. No início de cada unidade, existiam informações sobre os autores de cada documento e, no fim, além de se fazer sugestões metodológicas, arrolavam os pontos relevantes que o professor poderia destacar e apresentava questões para os alunos responderem. Os conteúdos da Coletânea foram divididos em unidades que tratavam da colonização européia, da América inglesa e da América Latina a partir da independência.

Comparando-se os conteúdos citados nos relatórios de estágios e as sugestões oficiais de conteúdos para o desenvolvimento das aulas com documentos, pôde-se estabelecer uma relação, tendo em vista que alguns dos conteúdos eram de História do Brasil e os documentos relacionam a História da América com a do Brasil. Mas as informações constantes nos relatórios não indicavam o uso pelos professores destes documentos oficiais, apenas o uso de livros didáticos, como o de Nadai e Neves sobre a História da América. Em sua totalidade os dados colhidos não foram suficientes para se estabelecer uma correlação entre as aulas e o uso dos documentos.

\section{Considerações sobre a prática pedagógica.}

As práticas pedagógicas dos professores de História do segundo grau nos anos estudados foram se alterando paulatinamente. Na medida em que a década de oitenta se desenrolou novas propostas de trabalho surgiram, como o uso de materiais didáticos, os professores passaram a adotá-los, como foi comprovado pelas fontes. Os livros didáticos assumiram um lugar secundário na prática cotidiana, sendo substituídos pelos materiais elaborados pelos próprios professores, como os fragmentos de textos, os recortes de jornais e revistas, entre outros. Foi possível identificar que os mesmos livros didáticos eram utilizados de modo contínuo durante os anos pesquisados, independentemente das 
alterações sofridas na grade curricular, como a alteração no número de aulas semanais de História ou as sugestões apresentadas pelos documentos oficiais. Verificou-se também, que os livros utilizados pelos professores para a pesquisa tornaram-se, com o tempo, de uso cotidiano.

A pesquisa demonstrou, ainda, que na prática cotidiana os professores faziam uso de alguns dos documentos contidos nos livros didáticos, mas não das coletâneas de documentos organizados pelos órgãos oficiais e distribuídos para as escolas. Essa prática da utilização de documentos dos livros didáticos tornou-se usual no final da década de 1980 e início da de 1990.

Apesar das alterações impostas às grades curriculares das escolas estaduais, nos anos da Reforma do Ensino, os conteúdos abordados pela disciplina História foram ampliados - o que é uma contradição-, já que ocorreu simultaneamente a redução da carga horária semanal. A Reforma impôs a obrigatoriedade do ensino de segundo grau profissionalizante, reduziu as aulas de História às duas séries iniciais desse nível de ensino. Mas, simultaneamente, os próprios órgãos governamentais organizaram e distribuíram sugestões de conteúdos e de atividades, além de inserirem novos conteúdos ao ensino de História, como o de História da América. Todas essas alterações curriculares acabaram por contribuir com o desenvolvimento de novas metodologias de ensino nas práticas pedagógicas dos professores.

\section{Referências Bibliográficas:}

ARRUDA, José Jobson de Andrade. História moderna e contemporânea. 17. ed. São Paulo: Ática, 1984.

História Antiga e Medieval. 2. ed. São Paulo: Ática, 1976.

BARBEIRO, Heródoto. História Geral. São Paulo: Harper \& Row do Brasil, 1984.

BATISTA, Antônio Augusto Gomes. Um objeto variável e instável: textos, impressos e livros didáticos. In: ABREU, Márcia (Org.) Leitura, História e História da Leitura. Campinas/SP: Mercado de Letras: Associação de Leitura do Brasil; São Paulo: Fapesp, 2002 .

BRASIL. Guia Metodológico para Cadernos MEC - História. Brasília: MEC: FENAME, 1971.

Conselho Federal de Educação. Parecer $n .^{\circ}$ 853, aprovado em 12 de novembro de 1971. Fixa o núcleo-comum para os currículos do ensino de $1^{\circ}$ e $2^{\circ}$ graus.

BURNS, Edward McNall. História da Civilização Ocidental. Trad. Lourival G. Machado, Lourdes S. Machado e Leonel Vallandro. 2. ed., 10. imp. rev. e atual. Porto Alegre: Globo, 1970. (2 vol.; título original, Western Civilizations: their History and their Culture).

CARBONE, Graciela. Libros escolares: una introducción a su análisis y evaluación. Buenos Aires: Fondo de Cultura Económica, 2003.

ESAÚ, Elias \& PINTO, Luiz Gonzaga de Oliveira. História do Brasil: estudo dirigido. $2^{\circ}$ grau. São Paulo: IBEP, [s.d].

História Geral da Civilização. São Paulo: Saraiva, 1975.

HUBERMAN, Leo. História da riqueza do homem. Trad. Waltensir Dutra. 20. ed. Rio de Janeiro: Zahar, 1984. (título original, Man's Wordly Goods).

Revista HISTEDBR On-line, Campinas, n.35, p. 96-107, set.2009 - ISSN: 1676-2584 
KOSHIBA, Luiz \& PEREIRA, Denise Manzi Frayze. História do Brasil. 6. ed. São Paulo: Atual, 1995.

MAIOR, Armando Souto. História Geral: para o ensino de $2^{\circ}$ grau e vestibulares. 23. ed. São Paulo: Companhia Editora Nacional, 1981.

MIMESSE, Eliane. O ensino profissional obrigatório de $2^{\circ}$ grau nas décadas de 70 e 80 e as aulas dos professores de História. Revista HISTEDBR On-line, v.26, p.105-113, 2007.

NADAI, Elza \& NEVES, Joana. História da América. São Paulo: Saraiva, 1979.

PEDRO, Antonio \& CÁCERES, Florival. História Geral. 2. ed. São Paulo: Moderna, 1982.

PEDRO, Antonio. História moderna e contemporânea. São Paulo: F.T.D., [s.d.].

PILETTI, Nelson. História do Brasil. 14. ed. São Paulo: Ática, 1996.

PRADO JÚNIOR, Caio. História econômica do Brasil. 30. ed. São Paulo: Brasiliense, 1985.

RELATÓRIOS DE ESTÁGIOS de observação e regência, 1972 a 1985. Laboratório de Ensino de História da Faculdade de Educação da USP.

SACRISTÁN, Jose Gimeno. $O$ currículo: uma reflexão sobre a prática. Trad. Ernani F. da F. Rosa. 3.ed. Porto Alegre: ArtMed, 2000. (título original, El curriculum: uma reflexión sobre la práctica).

SÃO PAULO. Proposta Curricular de História e Geografia para o $2^{\circ}$ grau. São Paulo: SEE: CENP, 1980.

Coletânea de documentos históricos para o $1^{o}$ grau- $5^{a}$ a $8^{a}$ séries. São Paulo: SEE: CENP, 1981.

Coletânea de Documentos de História da América para o $2^{o}$ Grau- $1^{a}$ série. São Paulo: SEE: CENP, 1981.

\section{Notas}

1. Os relatórios estudados foram divididos em relatórios de observação e relatórios de regências. Os de observação comumente eram cursados no primeiro semestre da disciplina, o aluno estagiário apenas observava o desenvolvimento da aula; e, os de regência ocorriam após o estágio de observação, nesse estágio os alunos participavam das aulas ativamente ministrando aulas e pequenos cursos, ou aplicando atividades.

2. Os relatórios de estágios eram muitas vezes realizados em duplas ou pequenos grupos. Esses relatórios continham trechos escritos comuns ao grupo e outros em que existiam comentários individuais de cada aluno estagiário, apresentando opiniões pessoais e considerações sobre o desenvolvimento da aula observada ou regida.

Artigo recebido em: 06/03/2009

Aprovado para publicação em: 21/07/2009 